\title{
Superiority of Alkali-Extracted Rice Protein in Bioavailability to Starch Degraded Rice Protein Comes from Digestion of Prolamin in Growing Rats
}

\author{
Takehisa KumAGAI ${ }^{1}$, Reiko WATANABE ${ }^{2}$, Mariko SAITO $^{1}$, \\ Toshiyuki WATANABE ${ }^{1}$, Masatoshi KUBOTA ${ }^{3}$ and Motoni KADOWAKI ${ }^{3}$ \\ ${ }^{1}$ Kameda Seika Co., Ltd., Niigata 950-0198, Japan \\ ${ }^{2}$ Course of Food and Nutrition, Department of Human Life Environments, Niigata Women's College, \\ Niigata 950-8680, Japan \\ ${ }^{3}$ Laboratory of Nutritional Regulation, Faculty of Agriculture, Niigata University, \\ Niigata 950-2181, Japan \\ (Received October 14, 2008)
}

\begin{abstract}
Summary The rice protein prepared from alkaline extraction (AE-RP) has high digestibility compared to that obtained from starch degradation (SD-RP) in in vitro digestion experiments, and alterations in the protein body (PB) structures were observed in AE-RP in the previous study. The improvement in the digestibility of AE-RP is probably a result of the structural change of $\mathrm{PB}$. The present study was carried out to elucidate the superiority of AE-RP compared to SD-RP in bioavailability in growing rats. There were no major differences between AE-RP and SD-RP in polypeptide compositions according to SDS-PAGE and their amino acid compositions. The equivalent body weight gain and similar growth curves in both AE-RP and casein (control) groups were obtained during the feeding period of $28 \mathrm{~d}$, and their values were significantly higher compared to the SD-RP group $(p<0.05)$. The protein efficiency ratio (PER) of the SD-RP (1.73) group was significantly lower than those of the AE-RP (1.87) and casein (1.84) groups $(p<0.05)$. The plasma lysine concentrations at the last stage of the feeding period in the AE-RP and SD-RP groups were approximate levels and were appreciably lower, compared to that of the casein group $(p<0.001)$. Portal plasma amino acid concentrations were determined after single administration $(4 \mathrm{~g} / \mathrm{kg})$ of two rice proteins in non-anaesthetized rats. All the amino acid concentrations in the 2 groups reached a maximum level at $30 \mathrm{~min}$ or $1 \mathrm{~h}$ and decreased to the pre-administration levels $6 \mathrm{~h}$ after the start of administration. The total amounts of three amino acids, leucine, valine and arginine, which appeared in the portal blood during the $6 \mathrm{~h}$ period after the start of administration of AE-RP, were higher than those of SD-RP $(p<0.05)$. Furthermore, $13 \mathrm{kDa}$ prolamin was detected with Western-blot analysis only in the feces of rats fed SD-RP. Consequently, these results indicate that the bioavailability of rice protein containing prolamin was improved by alkaline extraction.
\end{abstract}

Key Words rice protein, growth test, portal plasma amino acid, fecal prolamin, rat

The digestibility of cereal proteins is generally lower than that of animal proteins, and most cereal proteins have limiting amino acids (1-3). The true protein digestibility of cooked rice is $85-90 \%$ in humans (2), and the limiting amino acid is lysine, with rice being relatively low in threonine as well. Rice seed endosperm has two types of protein bodies, and prolamin is stored in the type I protein body (PB-I), and glutelin and globulin are stored in the type II protein body (PB-II) (4). Protein particles have been found in the feces of humans who ate cooked rice and were identified as PBI $(5,6)$. The previous study $(7)$ showed that the rice protein obtained by the alkaline extraction method (AE$\mathrm{RP})$ was superior in in vitro digestibility to that obtained by the starch degradation method (SD-RP), and alterations in the structure of PB were observed by immuno-

E-mail: t_kumagai@kameda.co.jp electron microscopic analysis only in AE-RP. We suggested that the alteration in the structure of AE-RP, especially prolamin, caused an improvement in digestibility and this could have applications in food manufacturing.

In this paper, we report the superiority of AE-RP in bioavailability in growing rats. Two types of rice protein were prepared from Oryza sativa L. cv. Koshihikari by alkaline extraction and starch degradation methods. The protein efficiency ratio (PER) of rice proteins was calculated by the body weight intakes of rats fed diets containing the rice proteins or casein and their food intakes for $28 \mathrm{~d}$. In addition, in order to verify whether the digestibility of prolamin had been improved, portal plasma amino acid concentrations were determined by the single administration of rice proteins to non-anaesthetized rats, and prolamin in the feces of rats was detected by Western blotting. 


\section{MATERIALS AND METHODS}

Preparation of rice proteins. Rice flour $(10 \%$ polished fraction) of Oryza sativa L. cv. Koshihikari was purchased from Niigata Seihun Co. Ltd. (Niigata, Japan). The rice proteins, AE-RP and SD-RP, were prepared on an extended scale ( $20 \mathrm{~kg}$ as rice flour) compared with the methods reported in our previous paper (7). Separation was performed by using continuous centrifuge $(\mathrm{H}-$ 130I1, Kokusan Co., Tokyo, Japan) at 3,000×g with a flow rate of $200 \mathrm{~L} / \mathrm{h}$. The crude protein $(\mathrm{CP})$ contents of the rice proteins were determined according to the Kjeldahl method using an N-to-protein factor of 5.95 (8).

Rice polypeptide fractionation and SDS-PAGE analysis. The rice polypeptides were extracted from AE-RP by the following treatment to obtain a standard prolamin for Western-blot analysis. Ten grams of powdered AE-RP

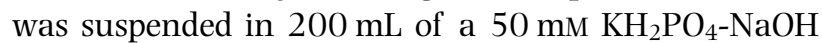
(pH 6.8) solution containing $0.5 \mathrm{M} \mathrm{NaCl}$ and $1 \mathrm{~mm}$ EDTA-2Na, and stirred at room temperature for $8 \mathrm{~h}$. The suspension was centrifuged at $10,000 \times g$ for $10 \mathrm{~min}$, and the precipitate was extracted 3 times. The precipitate was washed with distilled water and lyophilized. The combined extract was lyophilized after dialysis with distilled water (globulin-albumin fraction). Prolamin was extracted from the remaining precipitate with $200 \mathrm{~mL}$ of $60 \% n$-propanol for $8 \mathrm{~h}$, and the extraction was repeated 3 times. The combined extract was lyophilized after dialysis with distilled water (prolamin fraction) and the precipitate was washed with distilled water and lyophilized (residue). SDS-PAGE of rice proteins and rice polypeptide fractions was carried out according to Laemmli (9) on a $15 \%$ acrylamide gel. SDS-urea solution for protein extraction contained $8 \mathrm{~m}$ urea, 2\% SDS, 5\% 2-mercaptoethanol and $10 \%$ sucrose in a $50 \mathrm{~mm}$ Tris-HCl buffer (pH 6.8) (10). The samples (40 mg as protein) were immersed in $1 \mathrm{~mL}$ of SDS-urea solution and heated at $100^{\circ} \mathrm{C}$ for $10 \mathrm{~min}$. After centrifugation at $3,000 \times \mathrm{g}$ for $10 \mathrm{~min}, 2 \mu \mathrm{L}$ of supernatant was subjected to SDSPAGE. The gel was stained with Coomasie Brilliant Blue R 250 (Merck, USA). The densities of proteins were measured with NIH image software.

Diets and sample collection for growth test in rats. The animal experiments in the present study were performed in conformity with the Guidelines of the Committee for Animal Experimentation of Niigata University. Male, 3-wk-old Crlj:CD Sprague-Dawley rats, weighing about 45-50 g, were purchased from Charles River Japan, Inc. (Yokohama, Japan). The rats were given commercial pellets (Nosan, Yokohama, Japan) and water for $3 \mathrm{~d}$, before being fed the experimental diets. After acclimatization, the rats were randomly divided into three groups of the same average body weight. Each group consisted of eight rats. They were housed individually in stainless steel mesh cages and maintained at a constant temperature $\left(22 \pm 1^{\circ} \mathrm{C}\right)$, humidity $(60 \pm 5 \%)$ and $12 \mathrm{~h}$ light-dark cycle (06:0018:00), and given experimental diets and water ad libitum for $4 \mathrm{wk}$. The compositions of the experimental
Table 1. Composition of experimental diets. ${ }^{1}$

\begin{tabular}{lccc}
\hline & $\begin{array}{c}\text { Casein } \\
\text { diet }\end{array}$ & $\begin{array}{c}\text { AE-RP } \\
\text { diet }\end{array}$ & $\begin{array}{c}\text { SD-RP }^{3} \\
\text { diet }\end{array}$ \\
\hline & 22.7 & - & - \\
Casein $^{4}$ & - & 21.6 & - \\
AE-RP $^{4}$ & - & - & 24.8 \\
SD-RP $^{4}$ & 50.2 & 51.7 & 48.5 \\
$\beta$-Cornstarch & 10.0 & 10.0 & 10.0 \\
Sucrose & 5.0 & 5.0 & 5.0 \\
Cellulose & 7.0 & 7.0 & 7.0 \\
Soybean oil & 3.5 & 3.5 & 3.5 \\
Mineral mix & 1.0 & 1.0 & 1.0 \\
Vitamin mix & & & \\
L-Cystin & 0.3 & - & - \\
Choline bitartrate & 0.25 & 0.25 & 0.25 \\
tert-Butylhydroquinone & 0.0014 & 0.0014 & 0.0014
\end{tabular}

\footnotetext{
${ }^{1}$ Crude protein $(\mathrm{CP})$ contents were $20 \%$ in all experiment diets.

${ }^{2}$ AE-RP: rice protein by alkaline extraction.

${ }^{3} \mathrm{SD}-\mathrm{RP}$ : rice protein by starch degradation.

${ }^{4} \mathrm{CP}$ level: casein $88.1 \%$, AE-RP 92.6\%, SD-RP 80.6\%.

${ }^{5}$ Mineral mix: AIN-93G-MX (Nosan, Japan).

${ }^{6}$ Vitamin mix: AIN-93-VX (Nosan, Japan).
}

diets are shown in Table 1. Each experimental diet contained $20 \%$ casein, AE-RP or SD-RP as crude protein (CP).

The body weight and food intake were recorded daily during the feeding period. For the last week, the rats fed rice proteins were transferred to stainless steel metabolic cages individually, and the feces were collected for $7 \mathrm{~d}$. On the final day of the experiment, day 28 , blood was withdrawn from an abdominal vein into a heparinized syringe under anesthesia with sodium pentobarbital ( $50 \mathrm{mg} / \mathrm{kg}$ body weight). The collected blood was centrifuged $12,000 \times g$ at $4^{\circ} \mathrm{C}$ for $3 \mathrm{~min}$ and $100 \mu \mathrm{L}$ supernatant was obtained. In order to remove protein, the same volume of $3 \%$ sulfosalicylic acid was added to the supernatant and the mixed solution was separated by centrifugation as described above. The plasma samples were obtained and were frozen at $-80^{\circ} \mathrm{C}$ until amino acid analysis.

Portal blood collection to estimate in vivo digestion in rats. Male Crlj:CD Sprague-Dawley rats (255-280 g, 8 -wk-old) surgically fitted with portal vein cannula were purchased from Charles River Japan, Inc. Animals were housed individually in plastic cages, and had free access to a commercial stock diet (Nosan) and water for $2 \mathrm{~d}$ before the experiment. Room temperature and humidity were controlled at $22 \pm 1{ }^{\circ} \mathrm{C}$ and $60 \pm 5 \%$, respectively. The lighting was controlled for a $12 \mathrm{~h}$ light-dark cycle (06:00-18:00). After fasting about $18 \mathrm{~h}$ before initiation of the dosage, 16 rats were randomly divided into two groups based on their body weights. Rice proteins, AE-RP and SD-RP, were given as a single dose sample. The rice proteins (10 g as CP content) were mixed with $75 \mathrm{~mL}$ injection water (Fuso Pharmaceutical Industries Osaka, Japan). The suspension was administered ( $4 \mathrm{~g}$ as $\mathrm{CP} / \mathrm{kg}$ body weight) by a 
stomach radio sonde. Portal blood was serially collected through a heparinized disposable syringe (22G, Terumo, Japan) connected to a portal vein cannula on the neck. Before sampling, a plug on the cannula was sterilized with alcohol cotton, then $300 \mu \mathrm{L}$ of blood was collected at $0,0.5,1,2,3,4$, and $6 \mathrm{~h}$. The plasma was prepared in the same manner as described above, and frozen at $-80^{\circ} \mathrm{C}$ until amino acid analysis.

Amino acid analysis of rice proteins and rat plasma samples. Amino acid compositions of rice proteins and the plasma amino acid concentrations of rats were determined using an amino acid analyzer (JLC-500/V, JEOL Co. Ltd., Tokyo, Japan) according to the method of Chang et al. (11).

Western-blot analysis of prolamin. In order to identify $13 \mathrm{kDa}$ prolamin in feces, Western-blot analysis was carried out (12). The feces were dried at $60^{\circ} \mathrm{C}$ for $12 \mathrm{~h}$. The dietary rice proteins and the feces $(40 \mathrm{mg})$ were immersed in $1 \mathrm{~mL}$ of SDS-urea solution and heated at $100^{\circ} \mathrm{C}$ for $10 \mathrm{~min}$. After centrifugation at $3,000 \times g$ for $10 \mathrm{~min}$, the supernatant was diluted 50-fold with SDSurea solution and $15 \mu \mathrm{L}$ of the solution was subjected to SDS-PAGE. The proteins in the gel were transferred to a polyvinylidene difluoride membrane, and were then blocked overnight in blocking solution; TBS-Tween 20 (20 mM Tris-HCl, 137 mM NaCl, 0.1\% Tween 20, pH 7.6) containing $1 \% \mathrm{BSA}$ at $4^{\circ} \mathrm{C}$. After blocking, the membrane was incubated for $1 \mathrm{~h}$ with anti-13 $\mathrm{kDa}$ prolamin antibody (diluted with blocking solution 1 : 20,000, from Dr. T. Masumura, Kyoto Prefectural University). Following washing and incubation for $1 \mathrm{~h}$ with HRP-linked anti-rabbit IgG antibody (diluted $1: 10,000)$, the membrane was washed again and developed using ECL detection (Amersham Biosciences, NJ, USA). The bands were quantified by densitometric analysis.

Statistical analysis. Statistical analysis was performed with Statcel for Windows XP. The data were expressed as means \pm SE, and evaluated using Student's $t$-test and one-way analysis of variance followed by Fisher's PLSD post-hoc analysis. A level of $p<0.05$ was used as the criterion for statistical significance.

\section{RESULTS}

Characterization of rice proteins

The rice proteins used in this study included high CP contents: AE-RP, 92.6\%; SD-RP, 80.6\%, which are high grades, although the $\mathrm{CP}$ content of SD-RP was $12 \%$ lower than that of AE-RP. Table 2 shows the amino acid compositions of AE-RP and SD-RP. Both amino acid compositions were approximately equivalent between AE-RP and SD-RP except for sulfur-containing amino acids. The contents of methionine and cysteine in AE$\mathrm{RP}$ were significantly lower compared to those of SD-RP $(p<0.01$ and $p<0.001$, respectively). The amino acid composition of SD-RP was more similar to that of rice flour (10). The SDS-PAGE patterns of AE-RP, SD-RP and polypeptide fractions are shown in Fig. 1. Major polypeptides of $13 \mathrm{kDa}$ prolamin, $26 \mathrm{kDa}$ globulin, 22$23 \mathrm{kDa}$ and 37-39 kDa glutelin, and small quantities
Table 2. Amino acid composition of AE-RP and SD-RP.

\begin{tabular}{|c|c|c|}
\hline & AE-RP & SD-RP \\
\hline & \multicolumn{2}{|c|}{$\mathrm{mol} \%$} \\
\hline Glx & $15.80 \pm 0.06$ & $15.77 \pm 0.38$ \\
\hline Asx & $9.33 \pm 0.04$ & $9.08 \pm 0.04$ \\
\hline Leu & $8.46 \pm 0.03$ & $8.14 \pm 0.05$ \\
\hline Ala & $7.97 \pm 0.02$ & $7.96 \pm 0.15$ \\
\hline Gly & $7.71 \pm 0.02$ & $7.74 \pm 0.16$ \\
\hline Val & $6.76 \pm 0.02$ & $6.58 \pm 0.14$ \\
\hline Arg & $6.71 \pm 0.02$ & $6.40 \pm 0.24$ \\
\hline Ser & $6.39 \pm 0.27$ & $6.20 \pm 0.06$ \\
\hline Pro & $5.06 \pm 0.05$ & $5.10 \pm 0.16$ \\
\hline Phe & $4.50 \pm 0.03$ & $4.32 \pm 0.05$ \\
\hline Ile & $4.30 \pm 0.01$ & $4.14 \pm 0.06$ \\
\hline Tyr & $3.97 \pm 0.02$ & $3.55 \pm 0.33$ \\
\hline Thr & $3.89 \pm 0.02$ & $3.88 \pm 0.05$ \\
\hline Lys & $2.91 \pm 0.01$ & $2.98 \pm 0.06$ \\
\hline His & $2.61 \pm 0.11$ & $2.41 \pm 0.15$ \\
\hline Met & $1.65 \pm 0.03$ & $2.38 \pm 0.10^{* *}$ \\
\hline Cys & $1.15 \pm 0.01$ & $2.56 \pm 0.06^{* * *}$ \\
\hline Trp & $0.83 \pm 0.02$ & $0.85 \pm 0.07$ \\
\hline Total & 100.0 & 100.0 \\
\hline
\end{tabular}

Values represent means \pm SE $(n=3)$.

The data on rice proteins were evaluated by Student's $t$ test.

**, *** Significant differences from AE-RP $\left({ }^{* *} p<0.01\right.$, $* * * p<0.001)$.

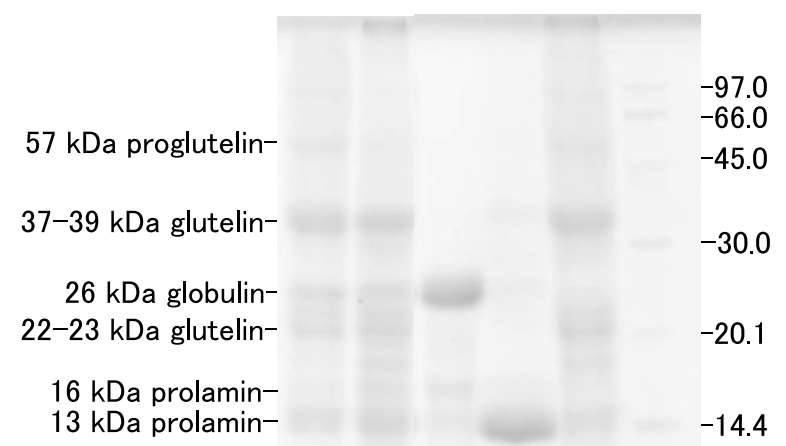

Fig. 1. SDS-PAGE patterns of rice proteins and the polypeptide fractions. Lane 1: AE-RP, rice protein by alkaline extraction. Lane 2: SD-RP, rice protein by starch degradation. Lane 3: Globulin-albumin fraction extracted with $0.5 \mathrm{M} \mathrm{NaCl}, 50 \mathrm{~mm} \mathrm{KH}_{2} \mathrm{PO}_{4}-\mathrm{NaOH}$. Lane 4: Prolamin fraction extracted with $60 \% n$-propanol. Lane 5: Residual protein after extracted with solvents. M: Molecular weights marker (kDa). AE-RP was used for preparation of polypeptide fractions.

of $16 \mathrm{kDa}$ prolamins and $57 \mathrm{kDa}$ proglutelin, were observed from both AE-RP and SD-RP. No quantitative difference in polypeptide bands was detected between AE-RP and SD-RP by densitometric analysis (7). Almost $26 \mathrm{kDa}$ globulin was removed by salt extraction (lane 
Table 3. Body weight, food intake and fecal weight in rats fed casein and rice proteins.

\begin{tabular}{lccc}
\hline & Casein & AE-RP & SD-RP \\
\hline Initial body weight $(\mathrm{g})$ & $64.2 \pm 1.7$ & $64.2 \pm 1.2$ & $64.2 \pm 1.1$ \\
Final body weight $(\mathrm{g})$ & $295.6 \pm 9.1^{\mathrm{a}}$ & $294.1 \pm 7.2^{\mathrm{a}}$ & $257.4 \pm 11.4^{\mathrm{b}}$ \\
Body weight gain $(\mathrm{g} / 28 \mathrm{~d})$ & $231.4 \pm 8.6^{\mathrm{a}}$ & $229.9 \pm 6.6^{\mathrm{a}}$ & $193.2 \pm 10.8^{\mathrm{b}}$ \\
Food intake $(\mathrm{g} / 28 \mathrm{~d})$ & $628.8 \pm 19.7^{\mathrm{a}}$ & $614.9 \pm 10.0^{\mathrm{a}}$ & $554.5 \pm 19.5^{\mathrm{b}}$ \\
Protein efficiency ratio & $1.84 \pm 0.02^{\mathrm{a}}$ & $1.87 \pm 0.04^{\mathrm{a}}$ & $1.73 \pm 0.05^{\mathrm{b}}$ \\
Dry fecal weight $(\mathrm{g} / \mathrm{d})^{1}$ & N.D. & $1.7 \pm 0.1$ & $1.9 \pm 0.1$ \\
\hline
\end{tabular}

Rats were fed experimental diets for $28 \mathrm{~d}$.

Values represent means \pm SE $(n=8)$.

The data were evaluated using one-way analysis of variance followed by Fisher's PLSD post-hoc analysis.

${ }^{\mathrm{a}, \mathrm{b}}$ Different letters show significant differences in diet groups $(p<0.05)$.

${ }^{1}$ Average for the last week.

N.D., not determined.

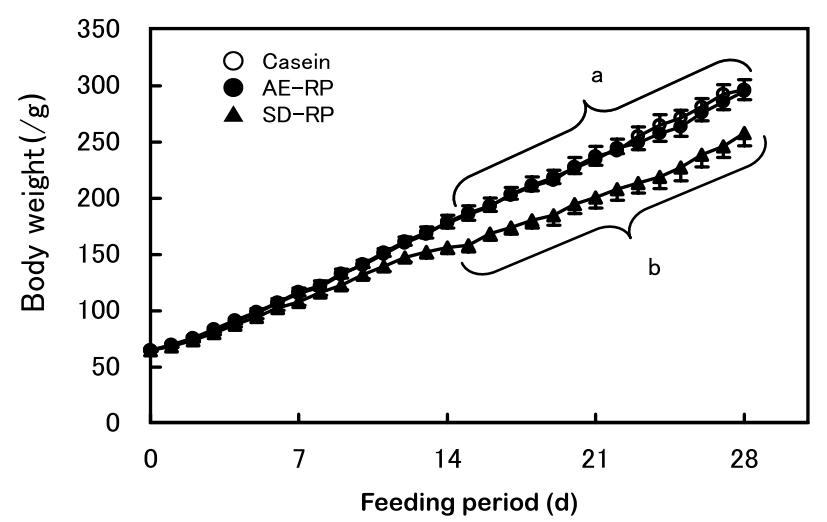

Fig. 2. Comparison of the body weights of rats fed casein or rice proteins for $28 \mathrm{~d}$. Rats were fed experimental diets for $28 \mathrm{~d}$. Values represent means \pm SE $(n=$ 8). Data were evaluated using one-way analysis of variance followed by Fisher's PLSD post-hoc analysis. ${ }^{a, b}$ Different letters show significant differences in diet groups (Casein and AE-RP vs SD-RP, $p<0.05$ ).

3). High density band of $13 \mathrm{kDa}$ prolamin, which had a purity of $79.5 \%$ according to densitometric analysis, was observed (lane 4; prolamin fraction), and was used a standard sample for Western-blot analysis.

Body weight, protein efficiency ratio and plasma essential amino acid concentrations in growth test

The effects of dietary proteins on growth performance in growing rats are summarized in Table 3, and the body weight changes of the rats are illustrated in Fig. 2. The growth study was carried out in 3 groups (AE-RP, SD-RP and casein as a control) for $4 \mathrm{wk}$, and was started at an average body weight of $64.2 \mathrm{~g}$. The maximum growth was obtained in the casein group. The SD-RP group showed slower growth, and the final body weight, weight gain and food intake were significantly lower compared to that of the casein group. A significant difference in the growth curve was observed from day 15, and was maintained in the latter stages of the feeding period of $28 \mathrm{~d}$. On the other hand, the AERP group showed the same growth as the casein group. There was no significant difference in the body weights between the two groups during the experimental period of $28 \mathrm{~d}$. The PER of the SD-RP (1.73) group was signifi-
Table 4. Plasma essential amino acids concentration.

\begin{tabular}{lccc}
\hline & Casein & AE-RP & SD-RP \\
\hline & & $\mathrm{nmol} / \mathrm{mL}$ \\
Leu & $104 \pm 4$ & $85 \pm 11$ & $86 \pm 8$ \\
Val & $153 \pm 7$ & $126 \pm 11$ & $130 \pm 8$ \\
Arg & $112 \pm 7$ & $130 \pm 9$ & $115 \pm 17$ \\
Phe & $51 \pm 3$ & $44 \pm 2$ & $49 \pm 5$ \\
Ile & $67 \pm 2$ & $55 \pm 4$ & $58 \pm 4$ \\
Thr & $263 \pm 14^{\mathrm{a}}$ & $186 \pm 14^{\mathrm{b}}$ & $143 \pm 24^{\mathrm{b}}$ \\
Lys & $475 \pm 28^{\mathrm{c}}$ & $286 \pm 29^{\mathrm{d}}$ & $255 \pm 19^{\mathrm{d}}$ \\
His & $42 \pm 2$ & $38 \pm 3$ & $41 \pm 4$ \\
Met & $46 \pm 2$ & $37 \pm 1$ & $42 \pm 4$ \\
Trp & $60 \pm 5$ & $51 \pm 5$ & $64 \pm 5$ \\
\hline EAA & $1,373 \pm 60^{\mathrm{e}}$ & $1,037 \pm 39^{\mathrm{f}}$ & $983 \pm 71^{\mathrm{f}}$ \\
\hline
\end{tabular}

Rats were fed experimental diets for $28 \mathrm{~d}$.

Values represent means \pm SE $(n=8)$.

Data were evaluated using one-way analysis of variance followed by Fisher's PLSD post-hoc analysis.

${ }^{\mathrm{a}-\mathrm{f}}$ Different letters show significant differences in diet groups ( $\left.{ }^{\mathrm{a}, \mathrm{b}} p<0.01,{ }^{\mathrm{c}, \mathrm{d}} p<0.001,{ }^{\mathrm{e}}{ }^{\mathrm{f}} p<0.05\right)$.

cantly lower than those of the AE-RP (1.87) and casein (1.84) groups.

Plasma essential amino acid concentrations at the end of the growth study are indicated in Table 4. The lysine concentrations of the AE-RP, SD-RP and casein groups were $286 \pm 29,255 \pm 19$ and $475 \pm 28 \mathrm{nmol} /$ $\mathrm{mL}$, respectively, and its level in the casein group was about 1.8 times higher than those of the AE-RP and SDRP groups $(p<0.001)$. The plasma threonine levels of the AE-RP and SD-RP groups were also lower compared to that of the casein group $(p<0.01)$.

Portal amino acid concentrations to estimate in vivo digestion

Portal plasma amino acid concentrations were determined after the single administration of rice proteins to estimate the difference between the digestion and absorption of two rice proteins, because the amino acid compositions of AE-RP and SD-RP were similar. In order to monitor the absorption under normal physiological conditions, portal blood was collected by portal 

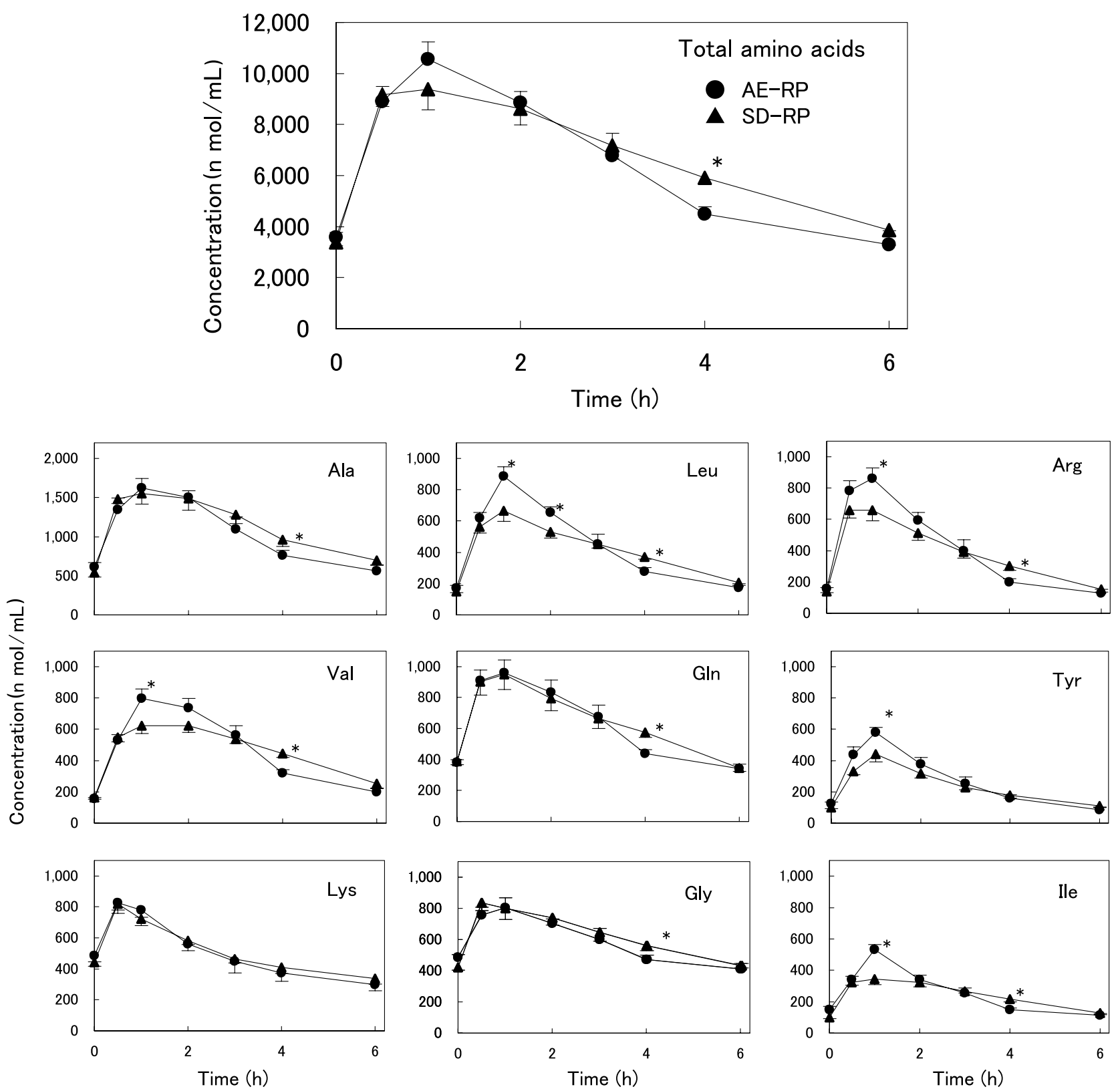

Fig. 3. Amino acid concentrations in portal blood of rats after single administration of rice proteins. Values represent means \pm SE $(n=7)$. The data were evaluated using Student's $t$-test. * Statistical difference in AE-RP and SD-RP $(p<0.05)$. Typical characteristic amino acids were selected.

vein canulation without anesthesia. An acute oral toxicity test had revealed that no death or abnormality occurred in rats administered $5 \mathrm{~g}$ AE-RP per $1 \mathrm{~kg}$ in weight (data not shown). Considering this, we administered $4 \mathrm{~g} / \mathrm{kg}$ to rats by stomach tube.

The time courses of total and typical free amino acid concentrations in portal blood are shown in Fig. 3. All the amino acid concentrations in the 2 groups reached a maximum level at $30 \mathrm{~min}$ or $1 \mathrm{~h}$ after administration. The values of leucine, arginine, valine, tyrosine, isoleucine and phenylalanine in the AE-RP group were significantly higher than those of the SD-RP group at $1 \mathrm{~h}$ $(p<0.05)$. Although the values of all amino acids except tyrosine, lysine, asparagine and tryptophan in the AERP group were significantly lower than those in the SDRP groups after $4 \mathrm{~h}(p<0.05)$, all the amino acid con- centrations decreased to the pre-administration levels after $6 \mathrm{~h}$. It was noteworthy that the time course curves of lysine were similar in both groups.

Table 5 shows the total amino acid amounts appearing in the portal blood during the $6 \mathrm{~h}$ period after the start of the administration of rice proteins. The values were calculated from slope and area of changes in amino acid concentration in portal blood during the $6 \mathrm{~h}$. Total amino acid amounts in both AE-RP and SDRP groups were equivalent. However, the amount of essential amino acid (leucine, valine, arginine, phenylalanine, isoleucine, threonine, lysine, histidine, methionine and tryptophane) in the AE-RP group was slightly higher than that of the SD-RP group. The amounts of leucine, valine and arginine in the AE-RP group were significantly higher than those of the SD-RP group 
Table 5. Total amino acid amounts appearing in the portal blood during $6 \mathrm{~h}$ after the start of administration of rice proteins.

\begin{tabular}{|c|c|c|c|c|c|}
\hline & \multicolumn{2}{|c|}{ AE-RP } & \multicolumn{2}{|c|}{ SD-RP } & \multirow{2}{*}{ AE-RP/ SD-RP } \\
\hline & $\mathrm{nmol} / \mathrm{mL} \cdot 6 \mathrm{~h}$ & $\%$ & $\mathrm{nmol} / \mathrm{mL} \cdot 6 \mathrm{~h}$ & $\%$ & \\
\hline Glu & $279 \pm 38$ & 1.5 & $289 \pm 60$ & 1.6 & 0.97 \\
\hline Gln & $1,612 \pm 186$ & 8.6 & $1,752 \pm 272$ & 9.4 & 0.92 \\
\hline Asp & $137 \pm 19$ & 0.7 & $135 \pm 17$ & 0.7 & 1.01 \\
\hline Asn & $648 \pm 155$ & 3.4 & $656 \pm 107$ & 3.5 & 0.99 \\
\hline $\mathrm{Leu}^{1}$ & $1,713 \pm 123^{*}$ & 9.1 & $1,481 \pm 90$ & 7.9 & 1.16 \\
\hline Ala & $2,927 \pm 336$ & 15.6 & $3,138 \pm 340$ & 16.8 & 0.93 \\
\hline Gly & $1,053 \pm 122$ & 5.6 & $1,141 \pm 165$ & 6.1 & 0.92 \\
\hline $\mathrm{Val}^{1}$ & $1,865 \pm 101^{*}$ & 9.9 & $1,609 \pm 128$ & 8.6 & 1.16 \\
\hline $\operatorname{Arg}^{1}$ & $1,645 \pm 164^{*}$ & 8.7 & $1,487 \pm 136$ & 8.0 & 1.11 \\
\hline Ser & $1,172 \pm 159$ & 6.2 & $1,244 \pm 122$ & 6.7 & 0.94 \\
\hline Pro & $1,036 \pm 84$ & 5.5 & $1,111 \pm 104$ & 6.0 & 0.93 \\
\hline $\mathrm{Phe}^{1}$ & $625 \pm 49$ & 3.3 & $550 \pm 41$ & 3.0 & 1.14 \\
\hline $\mathrm{Ile}^{1}$ & $892 \pm 35^{\#}$ & 4.7 & $791 \pm 56$ & 4.2 & 1.13 \\
\hline Tyr & $997 \pm 48^{\#}$ & 5.3 & $834 \pm 77$ & 4.5 & 1.20 \\
\hline Thr $^{1}$ & $864 \pm 66$ & 4.6 & $869 \pm 99$ & 4.7 & 0.99 \\
\hline Lys $^{1}$ & $503 \pm 66$ & 2.7 & $489 \pm 69$ & 2.6 & 1.03 \\
\hline His $^{1}$ & $342 \pm 29$ & 1.8 & $348 \pm 28$ & 1.9 & 0.98 \\
\hline $\operatorname{Met}^{1}$ & $223 \pm 30$ & 1.2 & $325 \pm 30^{*}$ & 1.7 & 0.69 \\
\hline Cys & $72 \pm 20$ & 0.4 & $181 \pm 33^{* *}$ & 1.0 & 0.40 \\
\hline $\operatorname{Trp}^{1}$ & $206 \pm 55$ & 1.1 & $183 \pm 34$ & 1.0 & 1.13 \\
\hline TAA & $18,811 \pm 1,668$ & 100.0 & $18,613 \pm 1,700$ & 100.0 & 1.01 \\
\hline EAA & $8,878 \pm 647$ & 47.2 & $8,132 \pm 662$ & 43.7 & 1.09 \\
\hline
\end{tabular}

Values represent means \pm SE $(n=7)$.

${ }^{1}$ Essential amino acids.

The data on rice proteins were evaluated by Student's $t$-test.

${ }^{*}, * *$ Statistical significance in AE-RP vs SD-RP $\left({ }^{*} p<0.05,{ }^{* *} p<0.01\right)$.

${ }^{*} p$ values for AE-RP vs SD-RP are 0.09.

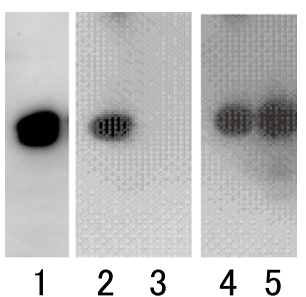

Fig. 4. Western blotting of $13 \mathrm{kDa}$ prolamin in rice proteins and in feces of rats fed AE-RP or SD-RP. Lane 1: Prolamin fraction as standard (Fig. 1, lane 4). Lane 2: AE-RP. Lane 3: Feces of rats fed AE-RP. Lane 4: SD-RP. Lane 5: Feces of rats fed SD-RP. Prolamin was not detected in feces of all rats fed AE-RP, but was detected in those of the SD-RP group.

$(p<0.05)$, and isoleucine and tyrosine in the AE-RP group showed a tendency to be high $(p=0.09)$. On the other hand, the methionine $(p<0.05)$ and cysteine $(p<0.01)$ in SD-RP were significantly higher than those of AE-RP. There was a slight difference between the descending order of the amino acid contents of the diet rice proteins and that of the amount of portal plasma amino acids. Alanine was the highest in the amount of portal plasma amino acids, though it was the fourth quantity in the amino acid compositions of AE-RP and SD-RP. The glutamic acid in both diet rice proteins was the highest, but the amounts of glutamine and glutamic acid decreased in the portal plasma.

Detection of $13 \mathrm{kDa}$ prolamin in feces

Thirteen-kDa prolamin in feces was examined by Western blotting (Fig. 4). Prepared prolamin (Fig. 1, lane 4) as a standard was stained one band (lane 1). Although prolamin was detected in both diet rice proteins (lane 2 and 4), it was only detected in the feces of the SD-RP group. Consequently, it was strongly suggested that prolamin in AE-RP could have been digested and absorbed in the digestive tract. In order to raise the sensitivity of detection, the analysis was performed by high concentration so that all bands were detected densely. Therefore, it was difficult to measure indigestive prolamin in SD-RP quantitatively by this method.

\section{DISCUSSION}

Generally, nutritional values of food proteins have been evaluated by PER, biological value and net protein utilization for biological methods. Therefore, the PER of two rice proteins (AE-RP and SD-RP) and casein (control) were examined with growth tests, in the first place. In order to explain the cause of the significant differ- 
ence for PER, plasma amino acid concentrations at the final stage of the growth test, portal amino acid concentrations without anaesthesia after the single administration of two rice proteins and existence of prolamin in the feces were determined. There were no major differences between AE-RP and SD-RP in percentages of the major polypeptides on the basis of SDS-PAGE patterns (Fig. 1), or in their amino acid compositions except for methionine and cysteine, which in AE-RP decreased compared to those of SD-RP (Table 2). It has been reported that mild alkali treatment of a sulfur-rich protein solution resulted in a degradation of cysteine (13, 14). A similar reaction is likely to occur with rice protein obtained by alkali processing.

In growth tests, the PER of the SD-RP group was significantly lower than those of the AE-RP and casein groups; therefore, the bioavailability of AE-RP was higher than that of SD-RP. Morita et al. $(15,16)$ have also reported that the body weight gain of the rice protein by the amylase digestion diet group was significantly lower than that of the casein diet group, and the rice protein by alkaline extraction was more effective at improving true protein digestibility in rats than amylase digestion. To elucidate the reason for the superiority of AE-RP in bioavailability, plasma lysine concentration, which is a limiting amino acid, was determined first. When investigating the influence of this limiting amino acid, the experimental diet protein level in the growth test is generally about $10 \%$ (17). In our preliminary growth test, the PER and body weight gain in 20\% AERP and 20\% casein groups were similar and were significantly higher than those of the $10 \%$ AE-RP group. Therefore, the $\mathrm{CP}$ level of the present experimental diets was $20 \%$. Since the plasma lysine concentrations of the AR-RP and SD-RP groups were nearly the same, it seems that the growth test on the CP level of $20 \%$ was not affected by the limiting amino acid (Table 4 ).

Portal plasma amino acid concentrations were measured after a single administration to directly compare the amino acid of the rice protein origin absorbed from the intestines of non-anaesthetized rats. Generally, alanine production is a well-known glucose alanine cycle and proceeds from glutamine and glutamic acid metabolism (18). There are many reports of transamination occurring during the absorption of the dicarboxylic amino acids, resulting in the appearance of alanine, when either glutaminic acid and/or aspartic acid is introduced into the small intestine (19-22). Rerat et al. reported the intestinal absorption of oligopeptides in a non-anaesthetized pig. The amounts of non-essential amino acid taken up by the intestinal tract were more than triple the quantities of essential amino acids. For individual amino acids, essential amino acids except for threonine and methionine were not well taken up by the intestinal tract (21). In our experiment, since the percentage of the amounts of alanine appearing in the portal blood increased compared to those of alanine in the dietary rice proteins, those of sum of glutamic acid and glutamine, and those of sum of aspartic acid and asparagine decreased. Therefore, it is difficult to com- pare the amounts of total amino acids. Essential amino acid amounts appearing in the portal blood of rats fed AE-RP were about $9 \%$ higher than that of the SD-RP group, but there were no significant differences. For percentages of individual essential amino acids, leucine, valine and arginine in the AE-RP group were significantly higher $(p<0.05)$, and isoleucine and tyrosine also showed a higher tendency than those of the SD-RP group $(p=0.09)$. Thus, it became clear that absorption ratios of the five essential amino acid amounts of the AE-RP group were $11-20 \%$ higher than those of the SD-RP group (Table 5).

Further, to elucidate the reason that the bioavailability of AE-RP was higher than that of SD-RP in growth tests, prolamin in a digestive residual substance, i.e., feces was analyzed qualitatively, by a method of investigating the digestion of prolamin directly, because the digestibility of AE-RP was remarkably higher compared to SD-RP in our in vitro digestion study (7). Prolamin in the feces collected for the last week was detected by Western blot analysis. Prolamin was not detected in all the feces of the AE-RP group, but was present in those of the SD-RP group. The percentage of prolamin content in rice proteins (AE-RP and SD-RP) was about 20\% by densitometric analysis (Fig. 1). Therefore, it seemed that the protein corresponding to prolamin came to be digested by alkaline treatment. Although the plasma free lysine concentrations in the AE-RP and the SD-RP groups were similar, PER and body weight gain in the AE-RP group were significantly higher compared to those of the SD-RP group. Total lysine amounts appearing in the portal blood during the $6 \mathrm{~h}$ period after the administration of rice proteins were the same values between the AE-RP and SD-RP groups. It has been known from amino acid sequencing and cDNA cloning of prolamin extracted from PB-I that prolamin contained little lysine (23-25). These reports support our results that there were no differences between the total lysine amounts appearing in the portal blood and the plasma free lysine concentrations in both the AE-RP and SD-RP groups. Additionally, we attempted to detect rice protein's polypeptides in the digestive tract with its antibodies to elucidate the details of its digestion. The results in our growth test and in the determination of portal amino acid levels were strongly supported by the appearance or disappearance of prolamin excretion in the feces. In conclusion, the superiority of AE-RP in its bioavailability to SD-RP is based on the increase in the total amino acid amounts absorbed in the digestive tracts, and the result is mainly due to the improved digestibility of prolamin contained in the rice protein prepared by alkaline extraction.

\section{Acknowledgments}

The authors would like to thank Dr. Takehiro Masumura of Kyoto Prefectural University for providing anti-prolamin antibodies. This work was supported in part by a Grant-in-Aid for Scientific Research (No. 17500568) to RW from the Japan Society for the Promotion of Science, and the Technology and Technical 
Development Program for building agribusiness in the form of utilizing concentrated know-how from the private sector in Japan.

\section{REFERENCES}

1) WHO. 1985. Energy and protein requirements. Report of a Joint FAO/WHO Expert Consultation. Tech. Rep. Ser. 522. WHO, Geneva.

2) WHO. 1973. Energy and protein requirements. Report of a Joint FAO/WHO/UNU Expert Consultation. Tech. Rep. Ser. 724. WHO, Geneva.

3) FAO. 1991. Protein quality evaluation. Food and Nutrition Paper 51.

4) Tanaka K, Sugimoto T, Ogawa M, Kasai Z. 1980. Isolation and characterization of two types of protein bodies in the rice endosperm. Agric Biol Chem 44: 1633-1639.

5) Tanaka Y, Hayashida S, Hongo M. 1975. The relationship of the feces protein particles to protein body. Agric Biol Chem 39: 515-518.

6) Tanaka Y, Resurreccion AP, Juliano BO, Bechtel DB. 1978. Properties of whole and undigested fraction of protein bodies. Agric Biol Chem 42: 2015-2023.

7) Kumagai T, Kawamura H, Fuse T, Watanabe T, Saito Y, Masumura T, Watanabe R, Kadowaki M. 2006. Production of rice protein by alkaline extraction improves its digestibility. J Nutr Sci Vitaminol 52: 467-472.

8) Miller L, Houghton JA. 1945. The micro-Kjeldahl determination of the nitrogen content of amino acid and proteins. J Biol Chem 159: 373-380.

9) Laemmli UK. 1970. Cleavage of structural proteins during the assembly of the head of bacteriophage T4. Nature 227: 680-685.

10) Iida S, Amano E, Nishio T. 1993. A rice (Oryza sativa L.) mutant having a low content of glutelin and a high content of prolamin. Theor Appl Genet 87: 374-378.

11) Chang KC, Lee CC, Brown G. 1986. Production and nutritional evaluation of high-protein rice flour. J Food Sci 51: 464-467.

12) Lin Y, Kumagai T, Kawamura H, Watanabe T, Kubota M, Fujimura S, Watanabe R, Kadowaki M. 2007. Effects of rice protein from two cultivars, Koshihikari and Shunyo, on cholesterol and triglyceride metabolism in growing and adult rats. Biosci Biotechnol Biochem 71: 694-703.

13) Nashef AS, Osuga DT, Lee HS, Ahmed AI, Whitaker JR,
Feeney RE. 1977. Effect of alkali on proteins. Disulfides and their products. J Agric Food Chem 25: 245-251.

14) Florence TM. 1980. Degradation of protein disulphide bonds in dilute alkali. Biochem J 189: 507-520.

15) Morita T, Kiriyama S. 1993. Mass production method for rice protein isolate and nutritional evaluation. J Food Sci 58: 1393-1396.

16) Morita T, Oh-hashi A, Kasaoka S, Ikai M, Kiriyama S. 1996. Rice protein isolates produced by two different methods lower serum cholesterol concentration in rats compared with casein. J Sci Food Agric 71: 415-424.

17) Mclaughlan JM, Illman WI. 1967. Use of free plasma amino acid levels for estimating amino acid requirements of the growing rat. J Nutr 93: 21-24.

18) Windmueller HG, Spaeth AE. 1980. Respiratory fuels and nitrogen metabolism in vivo in small intestine of fed rats. J Biol Chem 225: 107-112.

19) Matthews D, Wiseman G. 1953. Transamination by the small intestine of rat. J Physiol 239: 677-694.

20) Parsons DS, Volman-Mitchell H. 1974. The transamination of glutamate and aspartate during absorption in vitro by small intestine of chicken, guinea-pig and rat. $J$ Physiol 239: 677-694.

21) Rerat A, Simoes-Nunes C, Mendy F, Vaissade P, Vauglade P. 1992. Splanchnic fluxes of amino acids after duodenal infusion of carbohydrate solutions containing free amino acids or oligopeptides in the non-anaesthetized pig. Br J Nutr 68: 111-138.

22) Wu G. 1998. Intestinal mucosal amino acid catabolism. J Nutr 128: 1249-1252.

23) Masumura T, Shibata D, Hibino T, Kato T, Kawabe K, Takebe G, Tanaka K, Fujii S. 1989. cDNA cloning of an mRNA encoding a sulfur-rich $10 \mathrm{kDa}$ prolamin polypeptide in rice seeds. Plant Mol Biol 12: 123-130.

24) Mitsukawa N, Konishi R, Kidzu K, Ohtsuki K, Masumura T, Tanaka K. 1989. Amino acid sequencing and cDNA cloning of rice seed storage proteins, the $13 \mathrm{kDa}$ prolamins, extracted from typeI protein bodies. Plant Biotechnol 16: 103-113.

25) Mitsukawa N, Konishi R, Uchiki M, Masumura T, Tanaka K. 1999. Molecular cloning and characterization of cysteine-rich $16.6 \mathrm{kDa}$ prolamin in rice seeds. Biosci Biotechnol Biochem 63: 1851-1858. 